International gournal of Biological Sciences

Research Paper

(C) Ivyspring International Publisher. All rights reserved

\title{
Fluorouracil Selectively Enriches Stem-like Leukemic Cells in a Leukemic Cell line
}

\author{
Ling Zhang ${ }^{1 凶}$, Song Yang1, Yu-Juan He1, Hui-Yuan Shao', Li Wang2, Hui Chen³, Yu-Jie Gao', Feng-Xian \\ Qing', Xian-Chun Chen ${ }^{1}$, Liu-Yang Zhao', Shi Tan ${ }^{1}$
}

1. Key Laboratory of Laboratory Medical Diagnostics, Ministry of Education, Chongqing Key Laboratory, Faculty of Laboratory Medicine, Chongqing Medical University, Chongqing 400016, China

2. Department of Haematology, the First Affiliated Hospital, Chongqing Medical University, Chongqing 400016, China

3. Clinical Laboratory, the First Affiliated Hospital, Chongqing Medical University, Chongqing 400016, China

$\triangle$ Corresponding author: Ling Zhang, Faculty of Laboratory Medicine, Chongqing Medical University, 1\#, Yixueyuan Road, Chongqing 400016, China. Tel: +8623-68485223; Fax: +8623-68485005; Email: cqumszhl@sina.com

Received: 2010.05.20; Accepted: 2010.07.31; Published: 2010.08.03

\begin{abstract}
Recent studies have reported that cancer stem cells (CSCs) could be isolated from solid cancer cell lines, in which the purity of CSCs was higher than that from tumor tissues. Separation of CSCs from leukemic cell lines was rarely reported. In this study, CD34 $4^{+}$CD 38 stem-like cell subsets in human KG-Ia leukemic cell line were enriched by cytotoxic agent 5 -fluorouracil (5-FU). After 4 days incubation of KG-Ia cell line with 5 -FU $(50 \mu \mathrm{gg} / \mathrm{ml})$, the $\mathrm{CD} 34^{+} \mathrm{CD} 38^{-}$subpopulation of cell lines was enriched more than 10 times. The enriched cells had proliferate potential in vitro, low level of RNA transcription and Hoechst 33342 dye efflux ability, accompanied by high expression of ATP-binding cassette transporter protein ABCG2. Our findings suggest that treatment with 5-FU offers an easy method to isolate leukemic stem-like subpopulation. It can facilitate studies of leukemic stem cell biology and the development of new therapeutic strategies.
\end{abstract}

Key words: stem cell, leukemia, 5-fluorouracil, cell line, KG-1a

\section{Introduction}

Increasing evidence suggests that a subpopulation of cancer cells possesses extensive proliferative and self-renewal potential, and is responsible to tumor growth. These cells were later named cancer stem cells (CSCs) [1]. The existence of CSCs was established in human acute myeloid leukemia (AML) [2]. As the firstly recognized CSCs, the biological characteristics of leukemic stem cells (LSCs) have been extensively studied. Compared to a majority of relatively mature leukemic cells in bone marrow, LSCs possess qualities reminiscent of normal hematopoietic stem cells (HSCs) including self-renewal, the capacity of multi-lineage differentiation and the potential to proliferate extensively. Furthermore, LSCs are relatively quiescent and resistant to conventional chemothera- py. LSCs are critical for the initiation and perpetuation of leukemic disease, and their identification, characterization and isolation are essential to the development of new therapeutic strategies [3]. However, LSCs are only a small fraction of the total leukemic blasts, and they are difficult to identify and even more difficult to isolate. It is imperative to find a favorable method to isolate and purify LSCs, which may facilitate the understanding of biological characteristics of LSCs and provide basis for targeted therapy of leukemia in clinical practice.

Based on the biological similarities between LSCs and HSCs, the achievement in the exploration of surface markers of HSCs lays the foundation for the isolation and purification of LSCs. Furthermore, the 
emergence of new techniques also facilitates the identification of LSCs. An in vivo study with non-obese diabetic-severe combined immunodeficient (NOD/SCID) mice indicated the 'leukemia-initiating' subpopulation expressing CD34 but not CD38. Therefore, LSCs can be isolated based on the CD34 ${ }^{+} \mathrm{CD} 38^{-}$phenotype using flow cytometry (FCM) [4]. However, there is a considerable overlap between normal $\mathrm{CD}^{2} 4^{+} \mathrm{CD} 38^{-}$cells (HSCs) and malignant CD34 ${ }^{+} \mathrm{CD} 38^{-}$cells (LSCs). For the cells without specific phenotype, it is now possible to obtain CSC-like SP cells with FCM based on Hoechst 33342 efflux. Cells that exclude Hoechst 33342 have been termed "side population" (SP) cells [5]. SP cell analysis has been recently used to isolate CSCs from several types of cancers [6]. However, the level of SP cells in bone marrow of patients with leukemia is extremely low (median: $0.0016 \%$ ), and the harvested cells frequently do not express CD34, which is an important marker of LSCs [7]. In addition, although absence of SP was observed in Abcg2-deficient mice, they were viable and demonstrated no defect in steady state hematopoiesis [8]. Therefore, the SP analysis was seldom used to enrich LSCs. Recently, Creighton et al found that the residual cancer cells after chemotherapy had tumor-initiating features [9]. Based on the facts that CSCs were in the quiescent state and resistant to chemotherapy, chemotherapeutic drugs, which act on cycling cell populations, are less effective on stem cells and may be applied in the isolation of CSCs. Therefore, cycle-specific chemotherapeutic agents have been a novel strategy for LSCs enrichment.

No matter what kind of strategies used, extremely the low frequency of CSCs in any tumor tissue and the difficulty in discriminating between normal tissue stem cells and CSCs has made their purification a highly challenging goal. Established cancer cell lines had acquired unlimited proliferation ability and may in fact retain stem cell patterns of behavior, which could be an attractive alternative source of cells for CSCs research. Nowadays, CSCs have been successfully separated from cell lines derived from various solid cancers: including glioma [10], breast cancer [11], lung cancer [12], head and neck squamous carcinoma [13]. However, CSCs isolated from hematological malignancies cell lines were rarely reported. Stem-like cells have been found in multiple myeloma (MM) cell lines [14], but have never been identified in leukemia cell lines.

Cytotoxic agent 5-fluouracil (5-FU) had been applied to functional isolation and characterization of HSCs [15]. In the present study, we firstly enriched CD $34^{+}$CD38- subpopulation from KG-1a cell lines by
5-FU, and explored the stem-like biological features in vitro of the enriched cells.

\section{Materials and Methods}

\section{I Cell lines and culture conditions}

The human leukemic cell line KG1a was obtained from the ATCC (Manassas, VA 20108, USA). Cells were cryopreserved and then rapidly thawed and suspended in RPMI 1640 (GIBCO-BRL, Grand Island, NY) containing $4 \mathrm{mmol} / \mathrm{L}$ L-glutamine, 1.5 $\mathrm{g} / \mathrm{L}$ sodium bicarbonate, and $20 \%$ FBS (PAA, Austria). The line was maintained in an incubator at $37^{\circ} \mathrm{C}$, $95 \%$ humidity, and $5 \% \mathrm{CO}_{2}$. Passage was performed every 3 to 4 days (as recommended by the ATCC).

\subsection{Incubation of KG-I a cells with 5-FU}

5-FU (Sigma, USA) was dissolved in PBS. The cells at the logarithmic growth phase were harvested and seeded at a density of $2 \times 10^{5}$ cells $/ \mathrm{ml}$ in $5-\mathrm{ml}$ flasks. 5-FU was added to the RPMI1640 supplemented $15 \%$ FBS at a final concentration of $0,10,20$, $30,40,50,60$ and $80 \mu \mathrm{g} / \mathrm{ml}$, and cells were incubated at $37^{\circ} \mathrm{C}$ in a humidified air with $5 \% \mathrm{CO}_{2}$ for $24 \mathrm{~h}$. Each experiment was performed in triplicate. Trypans blue staining was performed and viable cells were counted followed by averaging. The dose-response curve was drawn to determine the optimal concentration. With optimal concentration of 5-FU, the cells were maintained for consecutive 6 days for the determination of optimal duration. The optimal concentration and time were used in subsequent experiments for selecting LSC-like subpopulation.

\subsection{Flow cytometry assay}

Single cell suspension ( $10^{6}$ cells $\left./ \mathrm{ml}\right)$ was obtained from KG-1a cells with or without 5-FU exposure. The cells were incubated with mouse anti-human CD45-PC5 antibody (Beckman Coulter, USA), CD34-PE antibody (Beckman Coulter, USA) and CD38-FITC antibody (Beckman Coulter, USA) at $25^{\circ} \mathrm{C}$ in dark for $25 \mathrm{~min}$. Subsequently, cells were rinsed with PBS twice and re-suspended in PBS containing $1 \%$ paraformaldehyde for fixation. Mouse anti- human IgG1-PC5, mouse anti- human IgG1-PE and mouse anti- human IgG1-FITC were used for isotype control respectively, and negative control was established too. We located the cells through two parameter (CD45/SSC) scatter diagram.

\subsection{In vitro colony formation assay}

The KG-1a cells with or without 5-FU exposure were suspended in RPMI 1640 medium. Colony formation assay was performed in semisolid culture medium containing 0.9 \% methylcellulose (Sigma, 
USA) and $10 \%$ FBS. The cell density was $1 \times 10^{3} / \mathrm{ml} /$ plate and cells were incubated at $37^{\circ} \mathrm{C}$ for $14 \mathrm{~d}$. Routine colony counts were performed under an inverted microscope (XDS-1B, China). Aggregates of 50 or more cells were scored as one colony and that of 3 50 cells as one cluster. Colony-forming rate $=$ number of colonies $/ 1000 \times 100 \%$. Three independent experiments were performed.

\subsection{Acridine orange staining}

The KG-1a cells were washed by the buffer derived from the acridine orange kit (KeyGEN, Nan jing, China), and then prepared for single cell suspension $\left(10^{6}\right.$ cells $\left./ \mathrm{ml}\right)$. One volume of acridine orange was added to 19 volumes of cell suspension, and cells were incubated in the dark at room temperature for $15 \mathrm{~min}$. Then, the cells were dropped onto slides and observed under inverted fluorescence microscope (TE2000U, Nikon). Green fluorescence was observed when acridine orange combined to DNA, and orange fluorescence observed when acridine orange bound to RNA. A total of 5 randomly selected fields $(\times 100)$ were used for counting. In each field, green and orange cells were counted, and the percentage of orange cells \{orange cells / (green cells + orange cells) $\times 100 \%\}$ was calculated. Three independent experiments were performed.

\subsection{Hoechst 33342 staining}

The KG-1a cells with or without 5-FU exposure were centrifuged and re-suspended in $2 \mathrm{ml}$ of RPMI 1640 containing $2 \%$ FBS. Then, the cells were incubated with Hoechst 33342 ( $5 \mu \mathrm{g} / \mathrm{ml}$; Sigma, USA) at $37^{\circ} \mathrm{C}$ for $90 \mathrm{~min}$ and shaken well every $15 \mathrm{~min}$. After washing with PBS twice, centrifugation was performed followed by smearing. Cells were observed under inverted fluorescence microscope. Blue nucleus was observed when Hoechst33342 bound to DNA in the nucleus of viable cell. The cells with Hoechst 33342 dye efflux ability showed negative/low staining. A total of 5 randomly selected fields $(\times 100)$ were used for counting. In each field, the Hoechst 33342 positive cells and total cells were counted, and the percentage of negative/low cells \{(total cells-positive cells) / total cells $\times 100 \%$ \} was calculated. Three independent experiments were performed.

\subsection{RT-PCR}

Total RNA of cells with or without 5-FU exposure was extracted with RNArose. Then $2 \mathrm{mg}$ of total RNA treated with DNA-free DNase was reverse-transcribed for cDNA synthesis and reverse transcription PCR (RT-PCR) was carried out. The primers for ABCG2 were: 5'-GCTGGGTAATCCCC AGGCCTCT-3', and 5'-AGAGATCGATGCCCTG
CTTTACCA-3'; and those for $\beta$-actin were $5^{\prime}$-AGCGAGCATCCCCCAAAGTT- $3^{\prime}$ and $5^{\prime}$-GGGC ACGAAGGCTCATCATT-3' (Invitrogen, Shanghai, China). The reaction was done in $50 \mu \mathrm{L}$ volume containing Expand High Fidelity buffer, $1.5 \mathrm{mM} \mathrm{MgCl}$, $200 \mu \mathrm{M}$ each dNTP, $0.2 \mu \mathrm{M}$ each primer and $2.5 \mathrm{U}$ Taq DNA polymerase. Cycling conditions were: $94^{\circ} \mathrm{C}$ for 5 min, followed by 35 cycles at $94^{\circ} \mathrm{C}$ for $30 \mathrm{sec}, 55^{\circ} \mathrm{C}$ for $30 \mathrm{sec}$ and $70^{\circ} \mathrm{C}$ for $50 \mathrm{sec}$, and a final extension step at $72^{\circ} \mathrm{C}$ for $10 \mathrm{~min}$. A total of $10 \mu \mathrm{l}$ of PCR product was loaded onto agarose gel for electrophoresis. Optical density of ABCG2 and $\beta$-actin was analyzed with a gel imaging analysis system (BIO-RAD, USA) and relative expression of ABCG2 was calculated.

\subsection{Western blot}

Western blot assay was used for detection of ABCG2 protein expression. A total of $50 \mu \mathrm{g}$ of proteins was loaded into sodium dodecyl sulfate polyacrylamide gel for electrophoresis and transferred onto PVDF member. The member was blocked with $5 \%$ non-fat milk overnight at $4^{\circ} \mathrm{C}$ followed by incubation with primary antibody (mouse anti-human ABCG2 monoclonal antibody; 1:100; R\&D, USA) and secondary antibody (goat anti-mouse antibody; $2 \mathrm{~h}$ ). Chemiluminescence detection was performed after been washed.

\subsection{Statistical analysis}

All data were presented as mean $\pm S D$ and SPSS13.0 statistical software was used for Student's paired t-test. A value of $P<0.05$ was considered statistically significant.

\section{Results}

\section{I Selection of Stem-like cells by exposure to 5-FU}

To determine a concentration of 5-FU selecting Stem-like cells, KG-1a cells were exposed at different concentrations ranging from $10 \mu \mathrm{g} / \mathrm{ml}$ to $50 \mu \mathrm{g} / \mathrm{ml}$ of 5 -FU for $24 \mathrm{~h}$. We found that 5-FU could exert killing effect on cells in a dose-dependent manner, and 50 $\mu \mathrm{g} / \mathrm{ml}$ was the minimal concentration under which the survival rate of KG-1a was minimal. During the exposure of KG-1a with $50 \mu \mathrm{g} / \mathrm{ml}$ 5-FU for $6 \mathrm{~d}$, results indicated the survival rate of KG-1a was in a time-dependent manner which reached the minimum on the day 4 (Figure 1). In subsequent experiments, KG-1a cells were incubated with $50 \mu \mathrm{g} / \mathrm{mL} 5$-FU for 4 $\mathrm{d}$ to select the stem-like cells.

\subsection{Enrichment of CD34 ${ }^{+} \mathrm{CD} 38^{-}$subpopulation}

After incubation with 5-FU, the KG-1a cells were dominated by $76.8 \% \mathrm{CD}^{+} 4^{+} \mathrm{CD} 38^{-}$subpopulation, 
accompanied by $23.0 \%$ CD34-CD38- cells and $0.2 \%$ $\mathrm{CD}{ }^{+}{ }^{+} \mathrm{CD} 38^{+}$cells. Among the cells without 5-FU exposure, the percentage of $\mathrm{CD}^{+} 4^{+} \mathrm{CD} 38^{-}$subset was only $7.02 \%$ and $85 \%$ KG-1a cells were CD34 ${ }^{+} \mathrm{CD} 38^{+}$

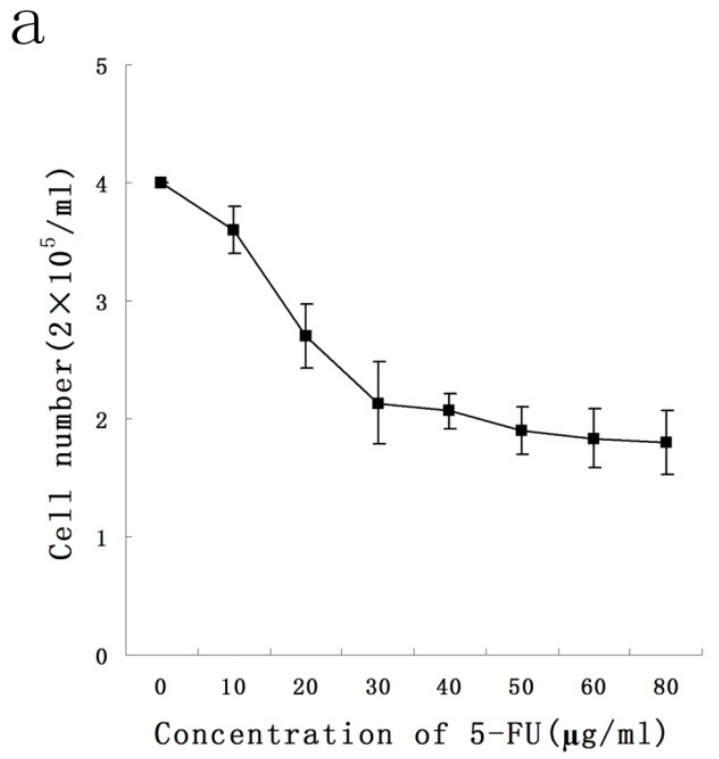

phenotype (Figure 2). These findings suggested after selecting by 5-FU, the proportion of $\mathrm{CD} 34^{+} \mathrm{CD} 38^{-}$ subpopulation was elevated more than 10 times.

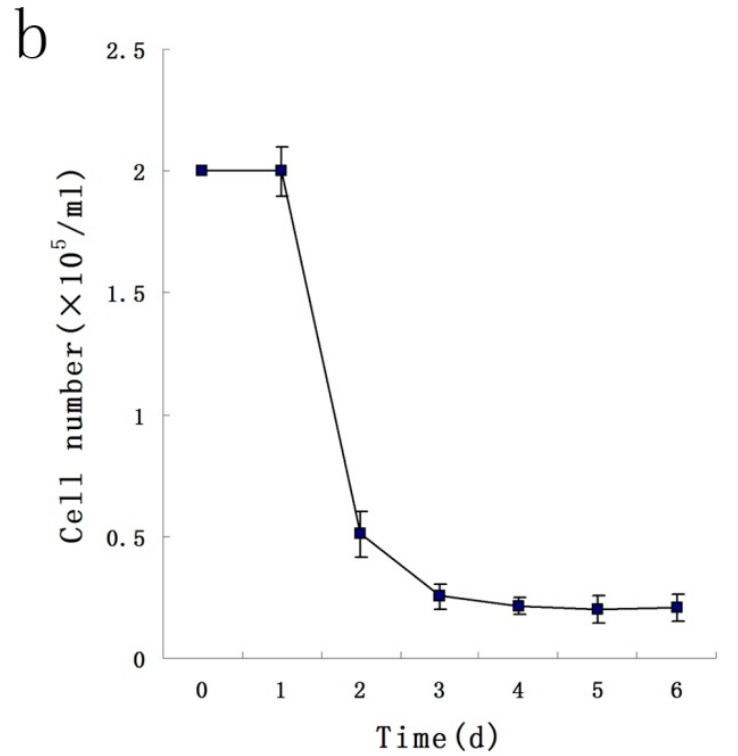

Figure I. Dose-and time-dependent curves of 5-FU incubation with KG-Ia cells. a, KG-Ia cells were incubated with different concentrations of 5-FU for $24 \mathrm{~h}$, and the killing effect of 5-FU was in a dose-dependent manner, with $50 \mathrm{\mu g} / \mathrm{ml}$ as the optimal concentration. $\mathbf{b}, \mathrm{KG}$ - la cells were incubated with $50 \mu \mathrm{g} / \mathrm{ml}$ 5-FU for different durations, and the killing effect of 5-FU was in a time-dependent manner, with $4 \mathrm{~d}$ as the optimal duration.
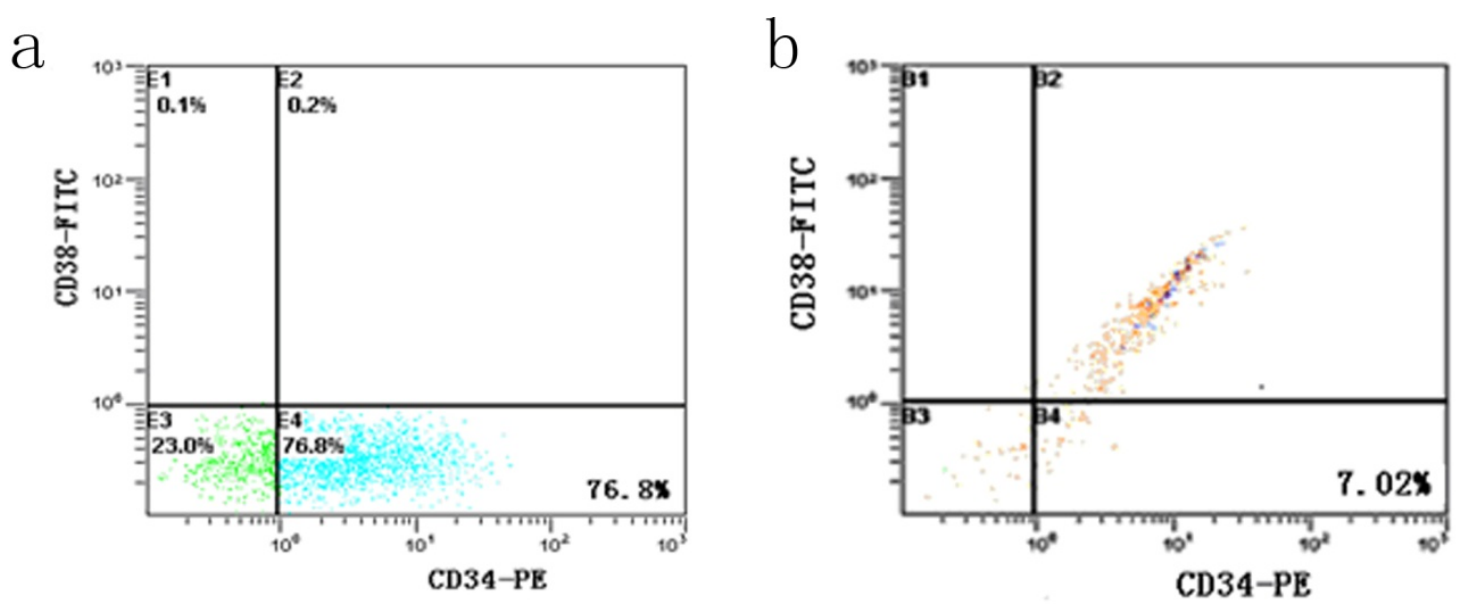

Figure 2. Detection of $\mathrm{CD} 34^{+} \mathrm{CD} 38$ subpopulation in KG-Ia cells. It shows the flow cytometric analysis of CD34 and

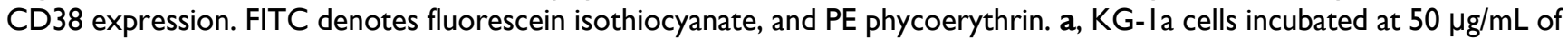
5-FU for $4 \mathrm{~d}$. The enriched cells had a high percentage of CD34-CD38- subpopulation. b, KG-Ia cells. 


\subsection{In vitro clonogenic activity}

The results indicated that the colony-forming rate in the cells received 5-FU treatment was (11.5 \pm 8.7$)$ $\%$, and the number of colony-forming cells was $50 \sim 80$. The colony-forming rate in the untreated cells was
$(5.4 \pm 2.1) \%$, majority of cells in this group formed clusters rather than colony in semisolid culture medium. Results demonstrated that the colony-forming rate in cells received 5-FU treatment was markedly higher than in untreated cells $(P<0.05)$ (Figure 3$)$.
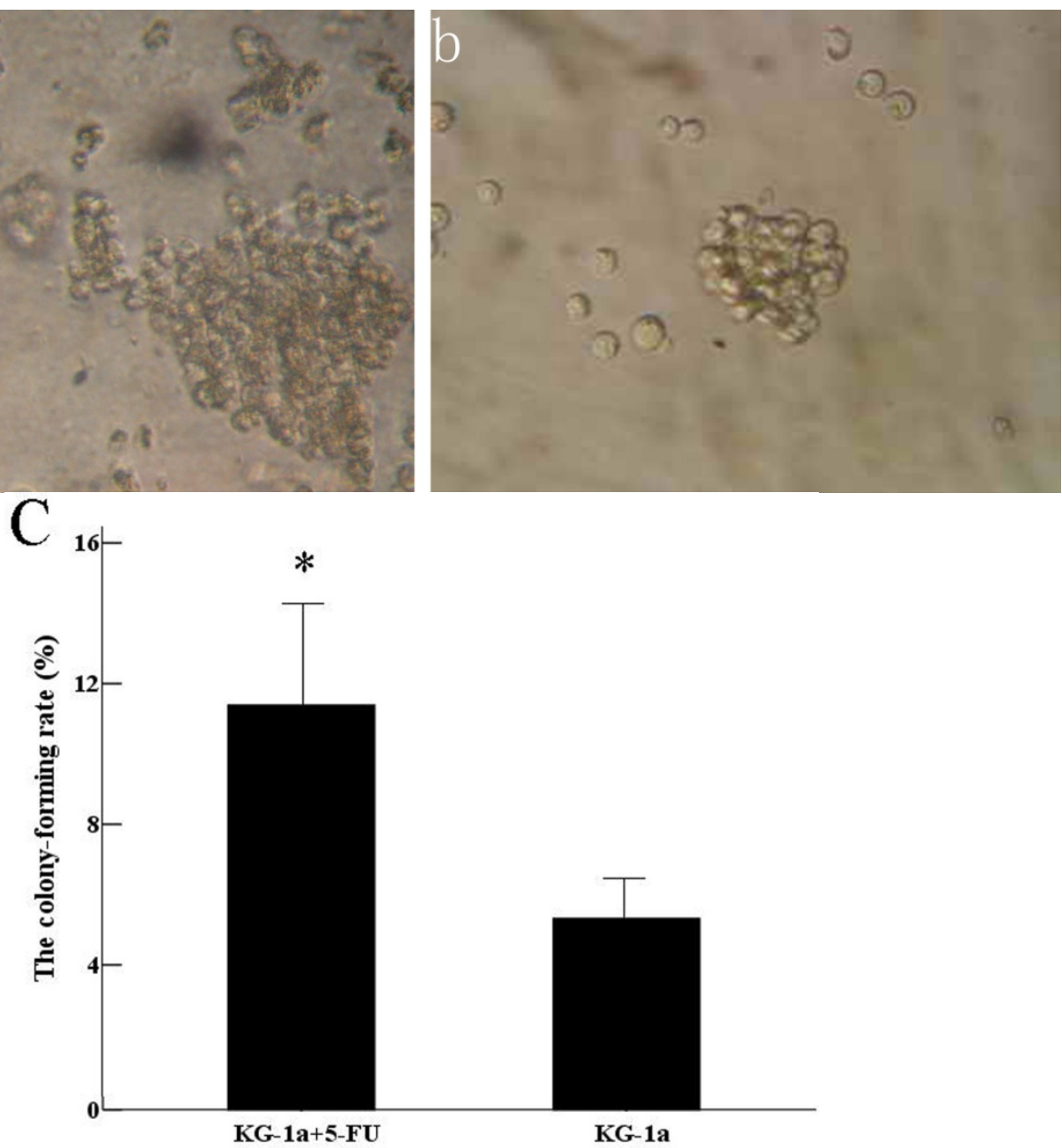

Figure 3. Colony formation assay in vitro semi-solid culture (Inverted microscope×400). a, (KG-Ia +5-FU) group: KG-Ia cells incubated at $50 \mu \mathrm{g} / \mathrm{mL}$ of 5 -FU for $4 \mathrm{~d}$. The enriched cells cultured in semisolid medium on $14 \mathrm{~d}$ formed clones and the number of colony forming cells was more than 50 . b, KG-Ia group: Majority of cells in this group only formed clusters. c, comparison on the colony-forming rate between two groups, ${ }^{*}, p<0.05$. Error bars correspond to mean \pm SD.

\subsection{Nucleic acid composition}

KG-1a cells were observed under inverted fluorescence microscope after acridine orange staining. Green fluorescence was observed in the cells received 5-FU treatment suggesting nucleic acid mainly consisted of DNA accompanied by low level of RNA. Orange fluorescence was dominantly noted in the untreated cells implying nucleic acid mainly consisted of RNA (Figure 4). The percentage of the cells with orange fluorescence in the 5-FU treated group was $(23.6 \pm 8.7) \%$, significantly lower than in 5-FU untreated group [(78.2 \pm 12.4$) \%, p<0.01]$. These findings suggested the 5-FU resistant cells had low-level of RNA transcription. 


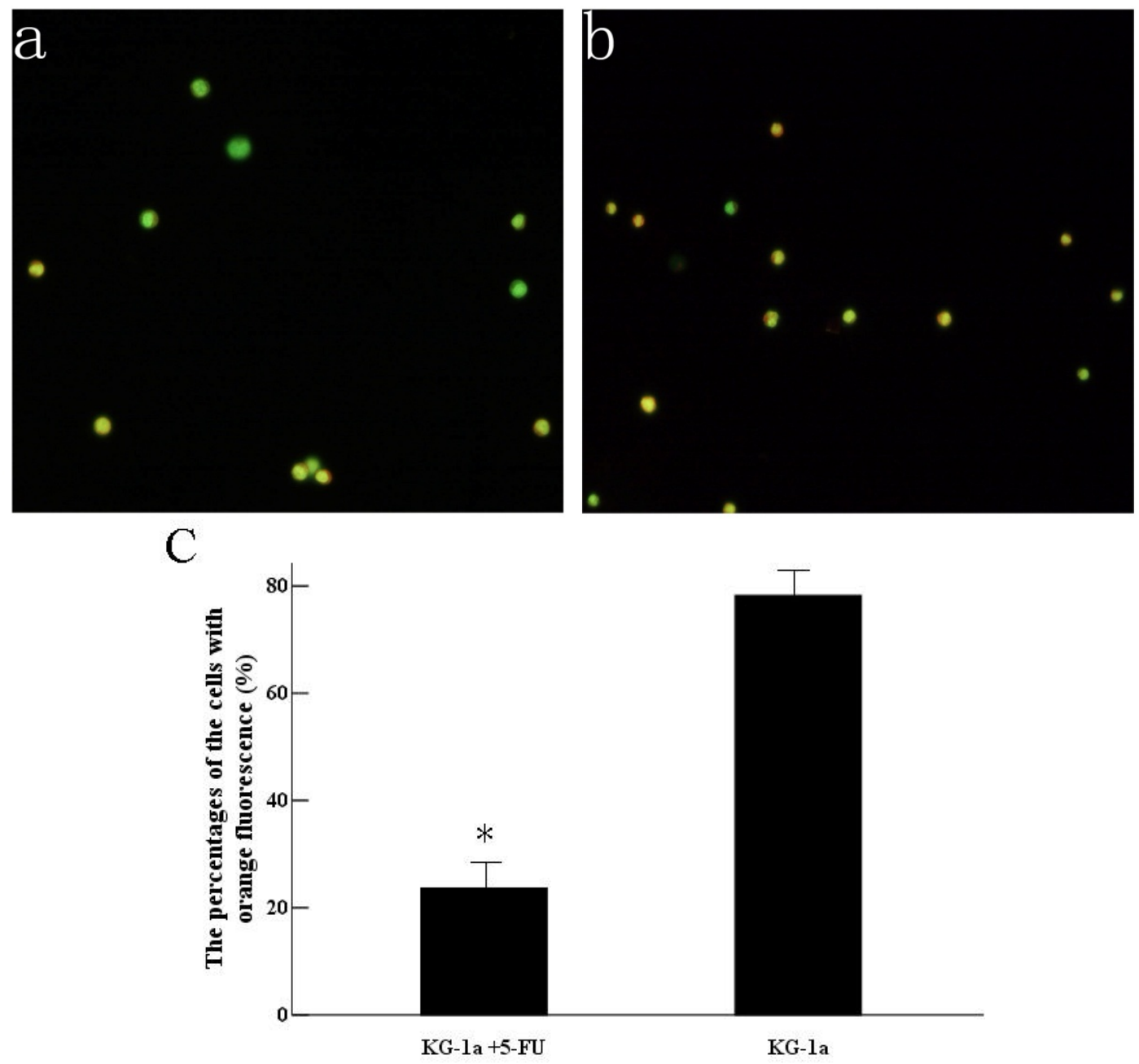

Figure 4. Acridine orange staining of nucleic acid in KG-I a cells (Fluorescence microscope $\times 200)$. a, (KG-la +5-FU) group: KG-la cells incubated at $50 \mu \mathrm{g} / \mathrm{mL}$ of 5 -FU for $4 \mathrm{~d}$. The enriched cells had low level of RNA content; b, KG-Ia group. c, comparison on the percentages of the cells with orange fluorescence between the two groups, ${ }^{*}, p<0.05$. Error bars correspond to mean \pm SD. The green fluorescence represents DNA content and the orange fluorescence represents RNA content. Three independent experiments were performed. A representative of the experimental results was shown.

\subsection{Hoechst 33342 efflux capacity}

After incubated with Hoechst 33342, the cells with Hoechst 33342 dye efflux ability showed negative/low staining. The negative/low cells rate was $15.9 \%$ in (KG-1a +5-FU) group, significantly higher than in KG-1a group $(6.6 \%, p<0.01)$. (Figure 5)

Figure 5. The Hoechst 33342 negative/low staining cells rate in KG-I a cells. KG-I a cells were stained by Hoechst 33342 and the cells were observed under inverted fluorescence microscope. Three independent experiments were performed. (KG-la $+5-F U)$ group: KG-la cells incubated at $50 \mu \mathrm{g} / \mathrm{mL}$ of $5-\mathrm{FU}$ for $4 \mathrm{~d}$. The enriched cells had a high percentage of negative/low staining cells $*, p<$ 0.05 . Error bars correspond to mean \pm SD.

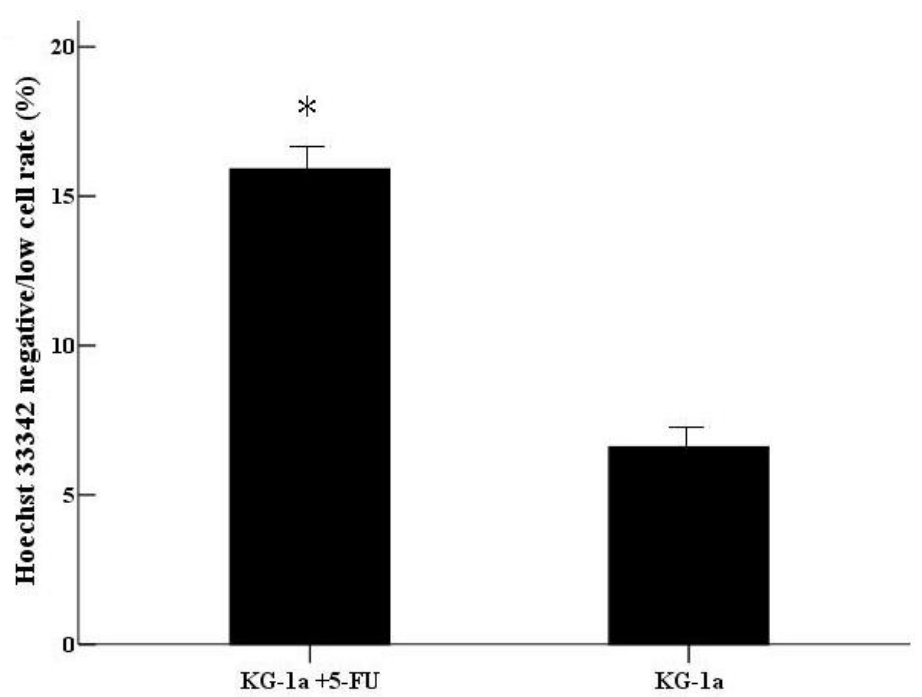




\subsection{Expression of ABCG2}

PCR assay indicated the expression level of ABCG2 mRNA (701 bp) in cells received 5-FU treatment was markedly higher than in the untreated cells.

a

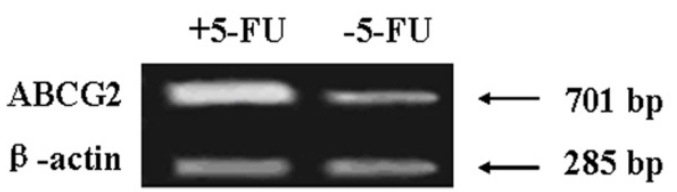

Western blot assay showed the expression of ABCG2 protein $(70 \mathrm{KDa})$ in cells received 5-FU treatment was dramatically higher than in untreated cells (Figure 6).

b

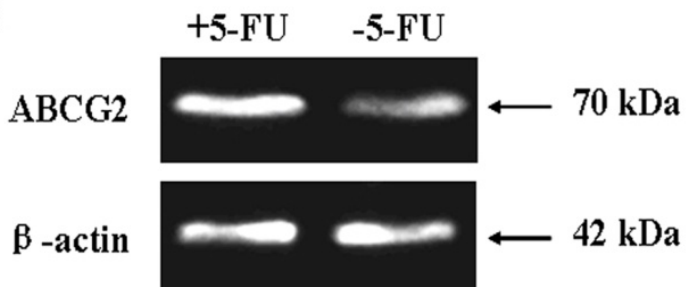

Figure 6. Expression of $A B C G 2$ mRNA and protein in KG-la cells. The enriched cells had high expression of $A B C G 2$ mRNA and protein. $\mathbf{a}$, analysis by RT-PCR of expression of ABCG2 mRNA. $\mathbf{b}$, analysis by Western blotting of the expression of $A B C G 2$ protein. +5-FU: KG-I a cells incubated with $50 \mu \mathrm{g} / \mathrm{mL}$ of 5 -FU for $4 \mathrm{~d}$; -5 -FU: $K G-I$ a cells without 5 -FU.

\section{Discussions}

Evidence suggests that CSCs are integral to the development of several forms of human cancer. Effort now focused on identifying and isolating CSCs. Cell-sorting technologies based on the CSCs markers or Hoechst dye exclusion have proven to be successful in the isolation of CSCs. However, the amount of CSCs isolated from fresh cancer tissues is extremely low. Furthermore, experiments with primary cancer cells are costly and difficult to control because of small sample size and the heterogeneous nature of the cellular among patient tissue samples. Recently, some studies indicated that solid cancer cell lines may provide us an alternative and convenient source of CSCs [16], but few studies reported the isolation of CSCs from hematological malignancies cell lines.

LSCs are mainly isolated from bone marrow through puncture, however, these cells are frequently contaminated by HSCs and in vitro culture is difficult, which limit the application of this method. In this study, we enriched stem-like subpopulation from KG-1a cell lines by cytotoxic agent 5-FU. Numerous leukemic cell lines have been established and acute myeloid leukemia (AML) from subtype M0 to M7 has their own cell lines. KG-1a cells are derived from undifferentiated cell line of AML subtype (AML-M0) and highly express stem cell-associated surface marker CD34 [17]. Therefore, KG-1a is an ideal cell model for enrichment of LSCs. It is well known that LSCs are in the quiescent state which makes them insensitive to chemotherapy. The cells in the proliferation phase are killed by cell cycle-specific chemotherapeutic agents. 5-FU, a pyrimidine antagonist, can lead to interruption of DNA synthesis and arrest of cellular division and proliferation. In the present study, it was used to isolate LSCs-like cells and the optimal conditions (50 $\mu \mathrm{g} / \mathrm{ml} 5$-FU for 4 days) were established. The percentage of $\mathrm{CD} 34^{+} \mathrm{CD} 38^{-}$subpopulation (76.8 \%) in KG-1a cells incubated with 5-FU was nearly increased by 10 folds. Although not all LSCs can be defined as CD $34^{+} \mathrm{CD} 38^{-}$[18], LSCs are detected only within the CD34 ${ }^{+} \mathrm{CD} 38$ - fraction of most AML samples $[2,19]$, so the $C D 34^{+} \mathrm{CD} 38$ - subpopulation was often used to represent LSCs in AML [20]. Colony-forming assay is an effective tool to test proliferating ability of single cell. The colony-forming rate of the cells received 5-FU treatment was elevated, indicating its proliferative potential in vitro. Meanwhile, it is also possible that cells under the stress condition (i.e., 5-FU exposure) simultaneously enter cell cycle after release from the stress (removal of 5-FU) and start proliferation. In the present study, the 5-FU resistant cells showed orange fluorescence in acridine orange staining test, which indicated the low-level of RNA transcription and quiescent consistent with stem cell biology. In addition, after 5-FU exposure, the percentage of Hoechst 33342 negatively stained cells increased. The cells that exclude fluorescent dyes Hoechst 33342 are defined side population (SP) cells and these cells share characteristics of CSCs, so further studies are required to detect the proportion of SP cells by FCM. Recent evidence suggests that the Hoechst 33342 dye efflux ability is probably mediated by an ABCG2-related mechanism and the expression of ABCG2 in LSCs was higher than in progenitors [21]. In this study, the cells received 5-FU treatment had high expression of ABCG2, which might originated from LSCs compartment and drug-resistant leukemic cells. In fact, some studies indicated that there were some overlap between drug-resistant cells and cancer stem cells. One study showed that the residual breast tumor cell popula- 
tions surviving after conventional treatment may be enriched for subpopulations of cells with tumor-initiating [9].

In vitro incubations with 5-FU have been used for enrichment of normal primitive hematopoietic stem cells [15], It has also been found 5-FU was applied to enrich LSCs from primary AML cells [22] and primary chronic myeloid leukemia (CML) cells [23], even though 5-FU seldom used for an antileukemic drugs in clinical practice. There are increasing evidence suggested that chemotherapeutic drugs could be applied to separate CSC subpopulations, for example, 1, 3-bis-(2-chloroethyl)-1-nitrosourea (BCNU) used for enrichment of CSCs subset in human brain glioma [24], epirubicin used in breast cancer [25], and 5-FU used in colorectal cancer [26]. Studies showed that LSCs in acute myeloid leukemia had the intrinsic drug efflux capacity [27], therefore, in the future study, more clinic relevant chemotherapy drugs (such as daunorubicin and mitoxantrone) should be tested in order to better simulate the clinic situation.

In conclusion, our experiment was a preliminary study on enrichment of stem-like cells subset with cytotoxic agent from leukemic cell lines. Furthermore, this assay would be verified in primary leukemic cells and other antileukemic drugs. In addition, the leukemia-initiating ability of the enriched cells compartment will need proof in animal models.

\section{Acknowledgements}

This project was supported by a grant from National Science Foundation of China (No. 30872418) and Science and Technology Research Foundation of Chongqing Municipal Education Commission (No. KJ050309). We would like to appreciate Mr. Qianglin Duan for critical reading of the manuscript.

\section{Conflict of Interests}

The authors have declared that no conflict of interest exists.

\section{References}

1. Reya T, Morrison SJ, Clarke MF, et al. Stem cells, cancer, and cancer stem cells. Nature. 2001; 414: 105-11.

2. Bonnet D, Dick JE. Human acute myeloid leukemia is organized as a hierarchy that originates from a primitive hematopoietic cell. Nat Med.1997; 3: 730-7.

3. Chan WI, Huntly BJ. Leukemia stem cells in acute myeloid leukemia. Semin Oncol. 2008; 35: 326-35.

4. Bhatia M, Wang JC, Kapp U, et al. Purification of primitive human hematopoietic cells capable of repopulating immune-deficient mice. Proc Natl Acad Sci U S A. 1997; 94: 5320-5.

5. Hirschmann-Jax C, Foster AE, Wulf GG, et al. A distinct "side population" of cells with high drug efflux capacity in human tumor cells. Proc Natl Acad Sci U S A. 2004; 101: 14228-33.
6. Wu C, Alman BA. Side population cells in human cancers. Cancer Lett. 2008; 268: 1-9.

7. Moshaver B, van Rhenen A, Kelder A, et al. Identification of a small subpopulation of candidate leukemia-initiating cells in the side population of patients with acute myeloid leukemia. Stem Cells.2008; 26: 3059-67.

8. Zhou S, Morris JJ, Barnes Y, et al. Bcrp1 gene expression is required for normal numbers of side population stem cells in mice, and confers relative protection to mitoxantrone in hematopoietic cells in vivo. Proc Natl Acad Sci U S A.2002; 99: 12339-44.

9. Creighton CJ, Li X, Landis M, et al. Residual breast cancers after conventional therapy display mesenchymal as well as tumor-initiating features. Proc Natl Acad Sci U S A. 2009; 106: 13820-5.

10. Qiang L, Yang Y, Ma YJ, et al. Isolation and characterization of cancer stem like cells in human glioblastoma cell lines. Cancer Lett. 2009; 279: 13-21.

11. Fillmore CM, Kuperwasser C. Human breast cancer cell lines contain stem-like cells that self-renew, give rise to phenotypically diverse progeny and survive chemotherapy. Breast Cancer Res. 2008; 10: R25.

12. Ho MM, Ng AV, Lam S, et al. Side population in human lung cancer cell lines and tumors is enriched with.stem-like cancer cells. Cancer Res. 2007; 67: 4827-33.

13. Huang D, Gao Q, Guo L, et al. Isolation and identification of cancer stem-like cells in esophageal carcinoma cell lines. Stem Cells Dev. 2009; 18: 465-73.

14. Matsui W, Huff CA, Wang Q, et al. Characterization of clonogenic multiple myeloma cells. Blood. 2004; 103: 2332-6.

15. Berardi AC, Wang A, Levine JD, et al. Functional isolation and characterization of human hematopoietic stem cells. Science. 1995; 267: 104-8.

16. Kondo T. Stem cell-like cancer cells in cancer cell lines. Cancer Biomark. 2007; 3: 245-50.

17. Koeffler HP, Billing R, Lusis AJ, et al. An undifferentiated variant derived from the human acute myelogenous leukemia cell line (KG-1). Blood.1980; 56: 265-73.

18. Taussig DC, Miraki-Moud F, Anjos-Afonso F, et al. Anti-CD38 antibody-mediated clearance of human repopulating cells masks the heterogeneity of leukemia-initiating cells. Blood, 2008; 112: 568-75.

19. Blair A, Hogge DE, Ailles LE, et al. Lack of expression of Thy-1 (CD90) on acute myeloid leukemia cells with long-term proliferative ability in vitro and in vivo. Blood. 1997; 89: 3104-12.

20. Florian S, Sonneck K, Hauswirth AW, et al. Detection of molecular targets on the surface of CD34+/CD38-- stem cells in various myeloid malignancies. Leuk Lymphoma. 2006; 47: 207-22.

21. de Figueiredo-Pontes LL, Pintão MC, Oliveira LC, et al. Determination of P-glycoprotein, MDR-related protein 1, breast cancer resistance protein, and lung-resistance protein expression in leukemic stem cells of acute myeloid leukemia. Cytometry B Clin Cytom. 2008; 74: 163-8.

22. Terpstra W, Ploemacher RE, Prins A, et al. Fluorouracil selectively spares acute myeloid leukemia cells with long- term growth abilities in immunodeficient mice and in culture. Blood. 1996; 88: 1944-50.

23. Holyoake $T$, Jiang $X$, Eaves $C$, et al. Isolation of a highly quiescent subpopulation of primitive leukemic cells in chronic myeloid leukemia. Blood. 1999; 94: 2056-64.

24. Kang MK, Kang SK. Tumorigenesis of chemotherapeutic drug-resistant cancer stem-like cells in brain glioma. Stem Cells Dev. 2007; 16: 837-47.

25. Yu F, Yao H, Zhu P, et al. let-7 regulates self renewal and tumorigenicity of breast cancer cells. Cell 2007; 131: 1109-23. 
26. Pang R, Law WL, Chu AC, et al. A Subpopulation of CD26+ Cancer Stem Cells with Metastatic Capacity in Human Colorectal Cancer. Cell Stem Cell. 2010; 6: 603-15.

27. Gerald G. Wulf, Rui-Yu Wang, Ingrid Kuehnle, et al. A leukemic stem cell with intrinsic drug efflux capacity in acute myeloid leukemia. Blood. 2001; 98: 1166-73. 